Terceiro Congresso Internacional ALEF sobre o Pensamento de J. G. Fichte: J. G. Fichte - Uma Vida Filosófica, uma Filosofia Viva

Gabriel Almeida Assumpção

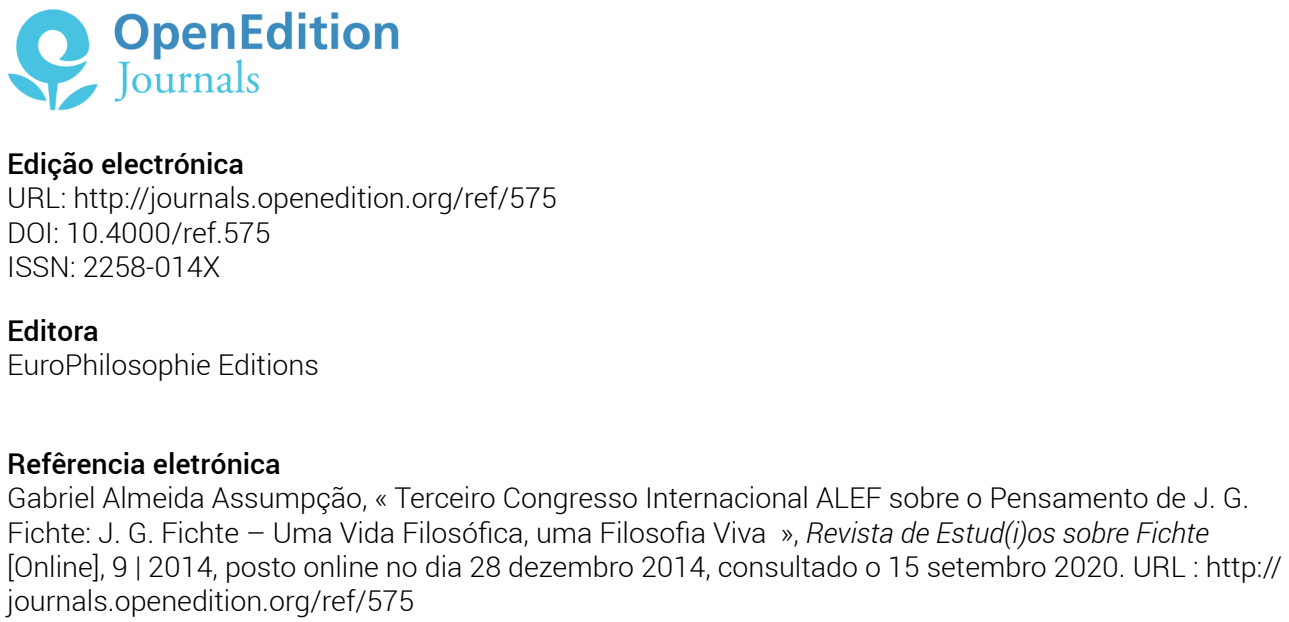

Este documento foi criado de forma automática no dia 15 setembro 2020.

() EuroPhilosophie 


\title{
Terceiro Congresso Internacional ALEF sobre o Pensamento de J. G. Fichte: J. G. Fichte - Uma Vida Filosófica, uma Filosofia Viva
}

\author{
Gabriel Almeida Assumpção
}

1 A 200 anos da morte de Johann Gottlieb Fichte (1762-1814), a ALEF (Associação Latinoamericana de Estudos sobre Fichte) - junto com a Internationale Fichte Gesellschaft e o Grupo de Pesquisa Idealismo Alemão (UFG), e contando com o apoio do Programa de Pós-Graduação em Filosofia da UFMG - dedicou um encontro internacional de pesquisa com o intuito de divulgar e discutir a obra de Fichte. Essa discussão se deu a partir de algumas das questões importantes que caracterizaram sua atividade filosófica, bem como a recepção de sua filosofia nos últimos dois séculos. Mais especificamente, o encontro foi pautado pelos seguintes temas: a natureza da liberdade, a relação entre vida e filosofia, a importância da educação para realização da liberdade, a atualidade do pensamento de Fichte.

2 Assim, deu-se continuação aos dois congressos anteriores - o primeiro em 2011, em Goiânia, Brasil, se intitulou "Primeiro Congresso Lationamericano sobre o pensamento de J. G. Fichte", entre os dias 7 e 10 de novembro de 2011. O segundo ocorreu em Valdivia, na Universidad Austral do Chile, entre os dias 13 e 15 de novembro de 2013, com o tema " Entre Revolución y Restauración: Fichte y la recepción romántica de su filosofia".

3 O terceiro congresso ocorreu na Universidade Federal de Minas Gerais, em Belo Horizonte, entre os dias 27 e 29 de agosto de 2014. O tema do congresso foi "J.G. Fichte Uma Vida Filosófica, uma Filosofia Viva", e contou com professores e pós-graduandos da Europa (Alemanha, Espanha e Itália) e América Latina (Argentina, Brasil y Chile), contando com um total de 27 participantes, tendo sido possível o encontro de estudiosos de Fichte de vários países.

4 As plenárias e comunicações - lidas em alemão, espanhol, italiano e português, com traduções das plenárias projetadas para o público geral - abordaram vários aspectos da 
filosofia de Fichte, desde a sua recepção por Schelling, Hölderlin e até mesmo Fernando Pessoa (Assumpção, Barreto, Souza, Vaccari, Vieira), passando para aspectos de sua filosofia do direito e seu pensamento social e político (Augier, Arrese Igor, Lima, Zöller). Também foi abordada a relação de Fichte com o ceticismo (Beckenkamp, Quevedo), Fichte e o ethos universitário (Oncina Coves), a leitura fichteana de Kant (Cunha, Santos) e uma crítica psicanalítico-foucaltiana a Fichte (Serrano Marín). Como não poderia deixar de ser - e fazendo jus ao tema do Congresso - foi abordada a relação entre Fichte e a vida do intelectual (Acosta), e também a doutrina da ciência como arte de viver (Ferraguto). Foram abordados desde a Tentativa de uma Crítica a toda Revelação (1792), obra do início da carreira de Fichte que lhe conferiu fama filosófica, até a relação entre vida e espírito no Fichte tardio (Klotz, Santoro). Em várias dessas palestras e comunicações, percebeu-se a importância da intersubjetividade e do reconhecimento na filosofia fichteana.

Uma seleção das comunicações e conferências será publicada no ano que vem, na Revista de Estud(i)os sobre Fichte, e teremos a possibilidade de divulgação escrita dos trabalhos apresentados e debatidos no Terceiro Congresso.

O alto número de submissões de resumos para participação, dos quais parte considerável veio de estudiosos da América Latina, mostra que houve interesse em nível nacional e internacional em participar do evento, e parece apontar para o desenvolvimento de uma "cultura de estudo" de Fichte, tanto no Brasil quanto em outros países da América Latina, como Argentina e Chile. Esperamos que os congressos continuem, sempre possibilitando a maior integração entre estudiosos no Brasil, na América Latina, e entre América Latina e Estados Unidos e países da Europa, como Itália, Espanha e Alemanha. Fotos do evento se encontram disponíveis no blog do mesmo: http://www.fichte2014ufmg.blogspot.com.br/p/fotos-do-evento.html. 